\title{
Inhibitory effects of miR-26b-5p on thyroid cancer
}

\author{
AIYA ZHOU ${ }^{*}$, GENGYU CHEN $^{2 *}$, XIANKUI CHENG ${ }^{3}, \mathrm{CHI}_{\text {ZHANG }}{ }^{2}, \mathrm{HAO} \mathrm{XU}^{2}$, \\ MING $\mathrm{QI}^{2}$, XIAO CHEN ${ }^{2}$, TIANTIAN WANG ${ }^{2}$ and LEPING $\mathrm{LI}^{4}$ \\ ${ }^{1}$ Department of Traditional Chinese Medicine, Shandong Provincial Hospital Affiliated to Shandong University, \\ Jinan, Shandong 250101; ${ }^{2}$ The Second Department of General Surgery, The Fourth Hospital of Jinan City, \\ Jinan, Shandong 250021; Departments of ${ }^{3}$ Pathology and ${ }^{4}$ General Surgery, Shandong Provincial \\ Hospital Affiliated to Shandong University, Jinan, Shandong 250101, P.R. China
}

Received September 10, 2018; Accepted March 14, 2019

DOI: $10.3892 / \mathrm{mmr} .2019 .10315$

\begin{abstract}
In order to examine the inhibitory effects of microRNA (miR)-26b-5p on thyroid cancer (TC), the clinicopathological features and pathological tissues of 67 patients were collected. The expression levels of miR-26b-5p were detected in TC and paracarcinoma tissues by quantitative polymerase chain reaction, and the association between miR-26b-5p expression and the clinicopathological features of the patients was analyzed using t-test or one-way analysis of variance. In addition, B-CPAP TC cells were infected with a lentivirus to induce miR-26b-5p overexpression and proliferation was detected by Cell Counting kit- 8 . Subsequently, migration and invasion were detected by Transwell and Matrigel assays, respectively, and the molecular mechanism of action was investigated by western blotting. The results demonstrated that the expression levels of miR-26b-5p were significantly lower in TC tissues compared with paracarcinoma tissues $(\mathrm{P}<0.01)$, and miR-26b-5p was associated with lymph node metastasis $(\mathrm{P}<0.05)$. In addition, overexpression of miR-26b-5p inhibited the proliferation, invasion and migration of B-CPAP cells. Western blot analysis demonstrated that the protein expression levels of phosphorylated glycogen synthase kinase- $3 \beta$ (pGsk-3 $\beta$ ) were decreased, and the expression of $\beta$-catenin was decreased in B-CPAP cells overexpressing miR-26b-5p. These results demonstrated that miR-26b-5p may exert antitumor
\end{abstract}

Correspondence to: Professor Leping Li, Department of General Surgery, Shandong Provincial Hospital Affiliated to Shandong University, 324 Jingwuweiqi Road, Jinan, Shandong 250101, P.R. China

E-mail: lplisd@163.com

Professor Tiantian Wang, The Second Department of General Surgery, The Fourth Hospital of Jinan City, 50 Shifan Road, Jinan, Shandong 250021, P.R. China

E-mail: wangtt409@aliyun.com

${ }^{*}$ Contributed equally

Key words: thyroid cancer, microRNA-26b-5p, lymph node metastasis, migration and invasion, glycogen synthase kinase-3 $\beta$ activity. In addition, at the molecular level, these effects may

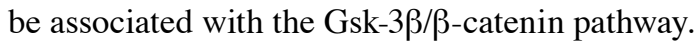

\section{Introduction}

Thyroid cancer (TC) is the most common type of endocrine malignancy (1); $90 \%$ of thyroid cancer cases are of poorly differentiated poorly differentiated thyroid carcinoma, the prevalence of which is increasing (2-4). Following treatment with specific methods, including surgery, radioactive iodine and thyroid-stimulating hormone inhibition, the majority of patients exhibit an improvement. However, there remains a risk of tumor recurrence and metastasis (5-7). Therefore, it is necessary to understand the occurrence and development of $\mathrm{TC}$, in order to identify specific effective targets for diagnosis and treatment.

MicroRNAs (miRNAs/miRs) are non-coding singlestranded small molecule RNAs that exert their biological function by inhibiting the transcription and translation of target genes, via binding to the $3^{\prime}$ non-coding region of the target mRNA $(8,9)$. Previous studies have demonstrated that miRNAs are closely associated with the occurrence and development of numerous tumors, including ovarian cancer, liver cancer, stomach cancer and breast cancer (10-13). Therefore, miRNAs have attracted increasing attention in tumor research.

Previous studies have reported that differentially expressed miRNAs in the tissues of patients with TC may be screened by gene chip technology $(14,15)$. These findings indicated that, in the tissues of patients with TC, the expression levels of miR-26b-5p are significantly lower compared with in normal tissues; in addition, it was revealed that miR-26b-5p may be associated with the occurrence and development of TC. Therefore, it was be hypothesized that miR-26b-5p may be a clinically relevant target for the treatment of TC.

However, the molecular mechanism underlying the anti-TC effect of miR-26b-5p remains unclear. A previous study using TargetScan predicted that the target gene for miR-26b-5p is glycogen synthase kinase-3 $\beta$ (Gsk-3 $\beta$ ) (16). It is well documented that the Gsk-3 $\beta / \beta$-catenin pathway serves an important role in the development of TC $(17,18)$.

In the present study, the expression levels of miR-26b-5p were detected in the tissues of patients with TC, and the 
association between miR-26b-5p and clinicopathological features was examined. Additionally, the inhibitory effect of miR-26b-5p on B-CPAP TC cells and its mechanism based on

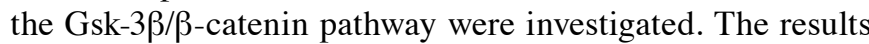
suggested that miR-26b-5p was downregulated in TC tissues and that miR-26b-5p expression may be associated with lymph node metastasis. In addition, miR-26b-5p was able to inhibit the proliferation, migration and invasion of TC, which may be associated with the Gsk-3 $\beta / \beta$-catenin pathway.

\section{Materials and methods}

Chemicals and materials. A total of 67 patients with TC undergoing surgical treatment at the Provincial Hospital of Shandong University were enrolled between February 2017 and September 2017. TC and corresponding paracarcinoma tissues were collected. TC was confirmed by pathological diagnosis and written informed consent was obtained from all patients. The 67 samples were collected and stored in liquid nitrogen until further use. The samples were collected from 17 men and 50 women, with an average age of 45 years (age range, 18-75 years).

RNAiso reagent, Prime Script 1st Strand cDNA Synthesis kit for reverse transcription (RT) and SYBR Premix Ex Taq for quantitative PCR (qPCR) were purchased from Takara Bio, Inc. Fetal bovine serum (FBS) and RPMI-1640 medium were purchased from Thermo Fisher Scientific, Inc. The Cell Counting Kit-8 (CCK-8) was purchased from Dojindo. Anti-GAPDH (cat. no. sc-32233), anti-Gsk-3 $\beta$ (cat. no. sc-71186), anti-phosphorylated (p) GSK-3 $\beta$ (cat. no. sc-81495) and anti- $\beta$-catenin (cat. no. sc-65480) were purchased from Santa Cruz Biotechnology, Inc. The lentiviral vectors were purchased from GeneChem, Inc. The Dual-Glo ${ }^{\mathrm{TM}}$ Luciferase Assay System and Lipofectamine 2000 were purchased from Promega Corporation.

Detection of $m i R-26 b-5 p$ expression. The expression levels of miR-26b-5p were detected in tissues from patients with TC by RT-qPCR, using the aforementioned materials. Total RNA was extracted from fresh frozen tissue using the RNAiso RNA extraction kit, according to the manufacturer's protocol, and total RNA concentration and purity were determined using a UV spectrophotometer. The primers were synthesized by Takara Bio, Inc. The miR-26b-5p primers were designed based on the sequence 5'-UCAAGUAAUUCAGGAUA GGU-3. U6 was used as an internal reference gene and its primer sequences were as follows: Forward 5'-GGAACGATACAG AGAAGATTAGC-3'; and reverse 5'-TGGAACGCTTCACGA ATTTGCG-3'. cDNA synthesis was conducted using an RT kit in a $10 \mu \mathrm{l}$ volume, according to the manufacturer's protocol. The RT temperature protocol was as follows: $37^{\circ} \mathrm{C}$ for $1 \mathrm{~h}$ and $85^{\circ} \mathrm{C}$ for 5 min. qPCR was performed on a Roche LightCycler 480 II instrument (Roche Molecular Diagnostics) as follows: denaturation $\left(95^{\circ} \mathrm{C}, 30 \mathrm{sec}\right), \mathrm{PCR}$ reaction for 45 cycles $\left(95^{\circ} \mathrm{C}\right.$ for $5 \mathrm{sec}, 60^{\circ} \mathrm{C}$ for $\left.30 \mathrm{sec}\right)$, melting $\left(95^{\circ} \mathrm{C}\right.$ for $5 \mathrm{sec}, 60^{\circ} \mathrm{C}$ for $1 \mathrm{~min})$, cooling $\left(50^{\circ} \mathrm{C}, 30 \mathrm{sec}\right)$. The final experimental data were standardized to the internal standard U6 and were analyzed using the $2^{-\Delta \Delta \mathrm{Cq}}$ method (19): $\Delta \mathrm{Cq}=\mathrm{Cq}_{\text {miRNA }}-\mathrm{Cq}_{\text {internal }}$ reference, $\Delta \Delta \mathrm{Cq}=\Delta \mathrm{Cq}_{\text {Sample }}-\Delta \mathrm{Cq}_{\mathrm{Max}}$. The maximum value of all data $\left(\Delta \mathrm{Cq}_{\text {Max }}\right)$ was used to normalize and correct the samples.
Cell culture. The B-CPAP cell line was donated by Professor Kennichi Kakudo (The Human Pathology Laboratory of Wakayama Medical University (Wakayama, Japan) (20) and the 293 cell line was purchased from GeneChem, Inc. The B-CPAP cell line was verified using the short-tandem repeat (STR) profiling. Briefly, DNA was extracted using Axygen genomic extraction kit and amplified using 20-STR amplification scheme (Shanghai Zhong Qiao Xin Zhou Biotechnology Co., Ltd.). The test of STR loci and sex gene Amelogenin was performed using an ABI 3730XL analyzer (Applied Biosystems; Thermo Fisher Scientific, Inc.). The cells were cultured in RPMI-1640 (B-CPAP) or Dulbecco's modified Eagle's medium (Sigma-Aldrich; Merck KGaA) growth medium supplemented with $10 \% \mathrm{FBS}, 100 \mathrm{U} / \mathrm{ml}$ penicillin and $100 \mu \mathrm{g} / \mathrm{ml}$ streptomycin at $37^{\circ} \mathrm{C}$ in a thermostatic incubator containing $5 \% \mathrm{CO}_{2}$. All experiments were performed on cells in the logarithmic growth phase.

Cell infection. miR-26b-5p mimics on a lentiviral vector were designed and synthesized by Shanghai GeneChem Co., Ltd., based on the following sequence: 5'-UUCAAGUAA UUCAGGAUAGGU-3'. Once the cells reached $80 \%$ confluence in 96-well plates, B-CPAP cells were infected with a miR-26b-5p-overexpressing lentivirus or an empty vector at a multiplicity of infection value of 50 . After $12 \mathrm{~h}$, the virus solution was aspirated and replaced with fresh medium. The fluorescence efficiency was observed after 48-72 h, and the infection efficiency was detected by RT-qPCR, and stably overexpressing cells and negative control (NC) were selected for subsequent experiments.

CCK-8 cell viability assay. Following digestion of miR-26b-5p-overexpressing cells and negative control cells with trypsin, the cells were adjusted to 5,000 cells/well and seeded in 96 -well plates at $37^{\circ} \mathrm{C}$ in an incubator containing $5 \% \mathrm{CO}_{2}$ saturated humidity. Cells were cultured for $24,48,72$ and $96 \mathrm{~h}$, and viability was detected using the CCK- 8 assay. Briefly, $10 \mu \mathrm{l}$ CCK-8 and $90 \mu \mathrm{l}$ fresh medium were added to each well. After $90 \mathrm{~min}$ at $37^{\circ} \mathrm{C}$, optical density values were determined at $450 \mathrm{~nm}$ using a microplate reader. The experiment was repeated at least three times.

Cell migration assay. Cell migration was detected using a Transwell assay. miR-26b-5p-overexpressing B-CPAP cells and negative control B-CPAP cells were re-suspended $\left(1 \times 10^{5}\right.$ cells $\left./ \mathrm{ml}\right)$ in RPMI-1640 medium, and a $200 \mu \mathrm{l}$ cell suspension was added to the upper chamber of Transwell plates. In addition, $600 \mu \mathrm{l}$ complete medium containing 5\% FBS was added to the lower chamber. After culturing for $18 \mathrm{~h}$, the cells in the lower chamber were washed twice with PBS, fixed with $95 \%$ ethanol at $37^{\circ} \mathrm{C}$ for $15 \mathrm{~min}$, and stained with hematoxylin at $37^{\circ} \mathrm{C}$ for $10 \mathrm{~min}$. The cells were then washed three times with water, air-dried and observed using light microscopy (magnification, $\mathrm{x} 200$ ).

Cell invasion assay. Cell invasion was detected using a Matrigel assay. Matrigel was thawed at $4^{\circ} \mathrm{C}$ overnight and thoroughly mixed with serum-free medium to obtain a 1:7 ratio on ice. Briefly, $70 \mu 1$ diluted Matrigel was added to the Transwell plates and incubated at $37^{\circ} \mathrm{C}$ for $30 \mathrm{~min}$, in order to polymerize 
the Matrigel. miR-26b-5p-overexpressing B-CPAP cells and NC B-CPAP cells were re-suspended $\left(1 \times 10^{5}\right.$ cells $\left./ \mathrm{ml}\right)$ in RPMI-1640 medium. Briefly, a $200 \mu 1$ cell suspension was added to the upper chamber and $600 \mu \mathrm{l}$ complete medium containing $10 \%$ FBS was added to the lower chamber. After culturing for $18 \mathrm{~h}$, the chamber was washed twice with PBS and the cells in the lower chamber were fixed with $95 \%$ ethanol at $37^{\circ} \mathrm{C}$ for $15 \mathrm{~min}$. The cells were then stained with hematoxylin at $37^{\circ} \mathrm{C}$ for $10 \mathrm{~min}$ and the chamber was washed with water three times. After natural air-drying, the chamber membranes were sealed with slides, and observed under an inverted light-transmitting microscope (magnification, x200). In total, five fields were randomly selected to count the number of cells.

Dual-luciferase enzyme assay. TargetScan (release no. 3.1; Whitehead Institute for Biomedical Research) was used to predict target genes of miR-26b-5p. The results revealed Gsk-3 $\beta$ to be a potential target, and this was verified via a dual-luciferase enzyme assay. Briefly, 293 cells (at a density of $4 \times 10^{5}$ cells $/ \mathrm{ml}$ ) were seeded in 24 -well plates and cultured for $24 \mathrm{~h}$. The luciferase reporter plasmids containing wild-type or mutant 3'-untranslated regions (UTRs) of Gsk-3 $\beta$ (Promega Corporation) were transfected into cells alongside miR-26b-5p mimics using Lipofectamine 2000 (transfection of $1 \mu \mathrm{g}$ plasmid) at $37^{\circ} \mathrm{C}$. After $\sim 48 \mathrm{~h}$ incubation at $37^{\circ} \mathrm{C}$, firefly and Renilla luciferase activities were assessed. Normalized relative light units represent firefly luciferase activity/Renilla luciferase activity.

Western blot analysis. The protein expression levels of Gsk-3 $\beta$, p-Gsk-3 $\beta$ and $\beta$-catenin in both miR-26b-5p-overexpressing and NC B-CPAP cells were detected via western blotting. Cellular proteins were extracted by using RIPA (Beijing Solarbio Science and Technology Co., Ltd.) containing phosphorylase inhibitors, and protein quantification was performed using a bicinchoninic acid kit. Subsequently, equal amounts of proteins $(30 \mu \mathrm{g})$ were separated using $10 \%$ SDS-PAGE, and were transferred to polyvinylidene difluoride membranes (EMD Millipore), which were blocked with $5 \%$ milk at $37^{\circ} \mathrm{C}$ for $1 \mathrm{~h}$. The membranes were then incubated overnight at $4^{\circ} \mathrm{C}$ with the following primary polyclonal antibodies: anti-GAPDH

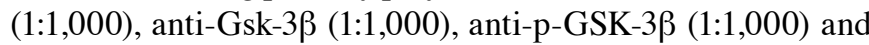
anti- $\beta$-catenin $(1: 1,000)$. Membranes were then incubated with a horseradish peroxidase-conjugated goat anti-rabbit secondary antibody (cat. no. abs20002; Absin Bioscience, Inc.; $1: 5,000)$ at $37^{\circ} \mathrm{C}$ for $1 \mathrm{~h}$. The membranes were imaged using enhanced chemiluminescence (ProteinSimple) and analyzed using Photoshop 6.0 (Adobe Systems, Inc.) and protein expression was normalized to GAPDH (dilution, 1:1,000).

Statistical analysis. All experiment was repeated at least 3 times, and data were analyzed using SPSS 22.0 statistical software (IBM Corp.), and a receiver operating characteristic (ROC) curve was analyzed and drawn using Prism 7 (GraphPad Software, Inc.). Measurement results are expressed as the mean \pm standard deviation. Student's t-test was used to compare two groups, whereas Spearman's correlation analysis was used to analyze the correlation between tumor stage and miR-26b-5p expression. $\mathrm{P}<0.05$ was considered to indicate a statistically significant difference.
Table I. Expression levels of miR-26b-5p in patients with thyroid cancer.

\begin{tabular}{|c|c|c|c|}
\hline Parameters & Cases & $\begin{array}{c}\text { Expression } \\
\text { of miR-26b-5p } \\
(\text { mean } \pm \text { SD) }\end{array}$ & P-value \\
\hline Sex & & & 0.439 \\
\hline Male & 17 & $4.70 \pm 2.48$ & \\
\hline Female & 50 & $5.34 \pm 3.06$ & \\
\hline Age (years) & & & 0.473 \\
\hline$\geq 45$ & 37 & $5.41 \pm 3.56$ & \\
\hline$<45$ & 30 & $4.89 \pm 3.20$ & \\
\hline Tumor size $(\mathrm{cm})$ & & & 0.916 \\
\hline$\geq 1$ & 48 & $5.20 \pm 3.03$ & \\
\hline$<1$ & 19 & $5.12 \pm 2.72$ & \\
\hline Lymph node metastasis & & & 0.015 \\
\hline Yes & 39 & $4.45 \pm 1.92$ & \\
\hline No & 28 & $6.19 \pm 3.72$ & \\
\hline TNM stage $^{\mathrm{a}}$ & & & 0.473 \\
\hline I & 35 & $4.37 \pm 0.80$ & \\
\hline II & 13 & $3.87 \pm 0.80$ & \\
\hline III & 19 & $4.60 \pm 0.49$ & \\
\hline Tissue & & & $<0.001$ \\
\hline Cancer & 67 & $5.18 \pm 2.92$ & \\
\hline Normal & 67 & $7.15 \pm 2.99$ & \\
\hline
\end{tabular}

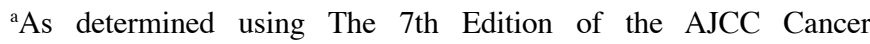
Staging Manual and the Future of TNM (21). AJCC, American Joint Committee on Cancer; miR-26b-56p, microRNA-26b-5p; $\mathrm{SD}$, standard deviation; TNM, Tumor-Node-Metastasis.

\section{Results}

Association between miR-26b-5p expression and clinicopathological features in TC. As shown in Table I, no significant differences in miR-26b-5p expression levels were identified between patients of different ages and sexes, nor was it associated with tumor size. In addition, Spearman's correlation analysis identified no significant correlation between miR-26b-5p expression and Tumor-Node-Metastasis (TNM) stage (21). The relative expression levels of miR-26b-5p in TC tissues $(5.18 \pm 2.92)$ were lower compared with in paracarcinoma tissues $(7.15 \pm 2.99)$ in the 67 patients $(\mathrm{P}<0.05$; Table I). Additionally, the expression levels of miR-26b-5p were significantly lower in patients with lymph node metastasis compared with in patients without lymph node metastasis $(\mathrm{P}<0.05)$.

As presented in Fig. 1, the area under the curve value was 0.7287 (95\% confidence interval: 0.6422-0.8152; specificity value: $65.67 \%$; sensitivity value: $76.12 \%$ ), which suggested that miR-26b-5p has high specificity and sensitivity in the clinical diagnosis of TC.

miR-26b-5p overexpression inhibits B-CPAP cell proliferation. Successful cell transfection was confirmed using RT-qPCR 


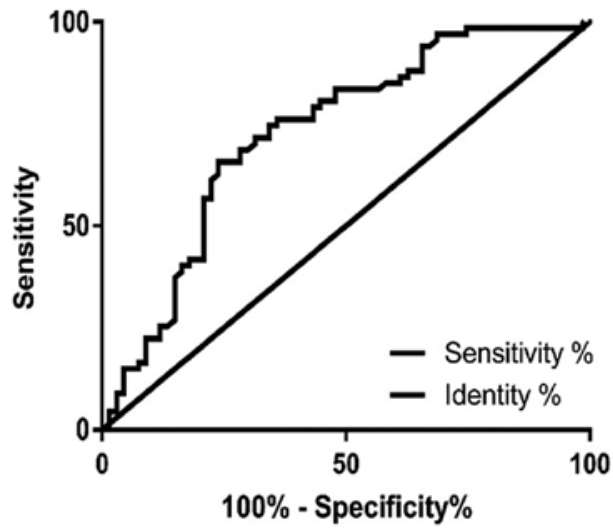

Figure 1. Receiver operating characteristic curve analysis of microRNA-26b-5p between thyroid carcinoma tissues and paracarcinoma tissues.

(Fig. 2A); no significant difference was detected in the expression levels of miR-26b-5p between the blank control group and the empty vector control group $(\mathrm{P}>0.05)$. Conversely, the expression levels of miR-26b-5p were significantly increased in the miR-26b-5p-overexpressing cells compared with in the blank control and empty vector control groups $(\mathrm{P}<0.05)$. Furthermore, after $24 \mathrm{~h}$, cell proliferation was reduced in the miR-26b-5p overexpression group compared with in the control group, thus suggesting that miR-26b-5p inhibited B-CPAP cell proliferation ( $\mathrm{P}<0.05$; Fig. 2B).

miR-26b-5p overexpression inhibits B-CPAP cell migration and invasion. The results of the migration and invasion assays are presented in Fig. 3. Briefly, the number of migratory and invasive B-CPAP cells in the control group was $216 \pm 5.6$ and $216.3 \pm 7.5$, respectively. However, the number of migratory and invasive B-CPAP cells was decreased in the miR-26b-5p overexpression group compared with in the control group, to $106.7 \pm 3.5$ and $61 \pm 3.5$, respectively $(\mathrm{P}<0.001)$. These results suggested that miR-26b-5p overexpression inhibited the migration and invasion of B-CPAP cells.

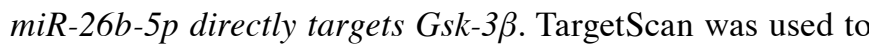
predict target genes of miR-26b-5p; Gsk-3 $\beta$ was predicted as a target gene, since the 3'-UTR of Gsk-3 $\beta$ contains numerous binding sites for miR-26b-5p (Fig. 4A). As presented in Fig. 4B, the luciferase reporter assay demonstrated that miR-26b-5p significantly inhibited the luciferase activity in the wild-type Gsk-3 $\beta$ group in vitro. Conversely, mutations in the binding site restored luciferase activity.

miR-26b-5p downregulates the protein expression levels of $p$ Gsk-3 $\beta$ and $\beta$-catenin in $B$-CPAP cells. The results of western blotting are presented in Fig. 5 . In the control group, $\beta$-catenin was highly expressed, whereas, in the miR-26b-5p overexpression group, the protein expression levels of $\beta$-catenin were significantly decreased $(\mathrm{P}<0.01)$. In addition, pGsk-3 $\beta$ in the miR-26b-5p overexpression group was decreased compared with in the control group $(\mathrm{P}<0.01)$. These results indicated that miR-26b-5p may exert antitumor activity by downregulating the expression of $\beta$-catenin and pGsk-3 $\beta$ proteins in B-CPAP cells.
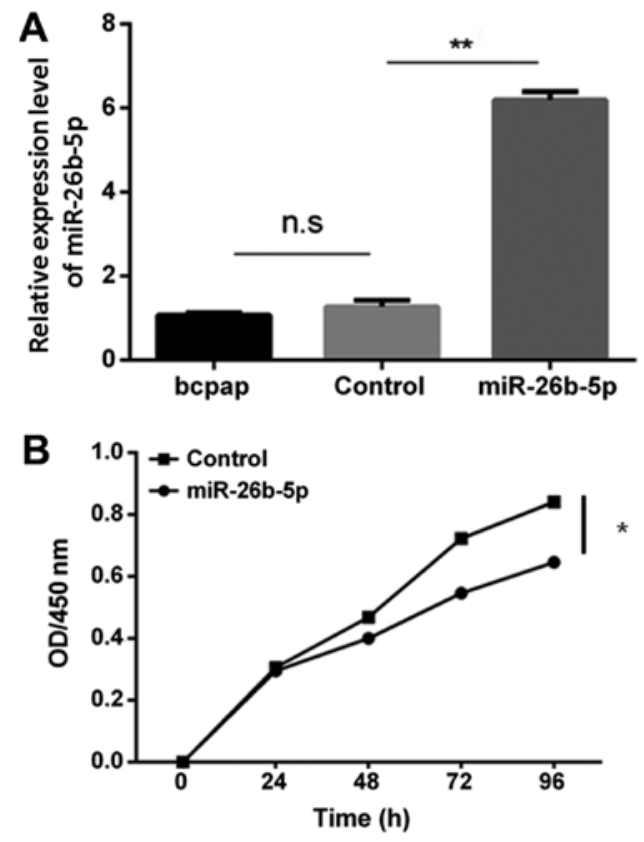

Figure 2. miR-26b-5p overexpression inhibits BCPAP cell proliferation (A) Relative expression levels of miR-26b-5p in BCPAP cells. (B) Cell Counting Kit- 8 assay was used to detect proliferation of cells with or without miR-26b-5p overexpression. ${ }^{*} \mathrm{P}<0.05$ and ${ }^{* *} \mathrm{P}<0.01$. miR-26b-5p, microRNA-26b-5p; ns, not significant; OD, optical density.

A
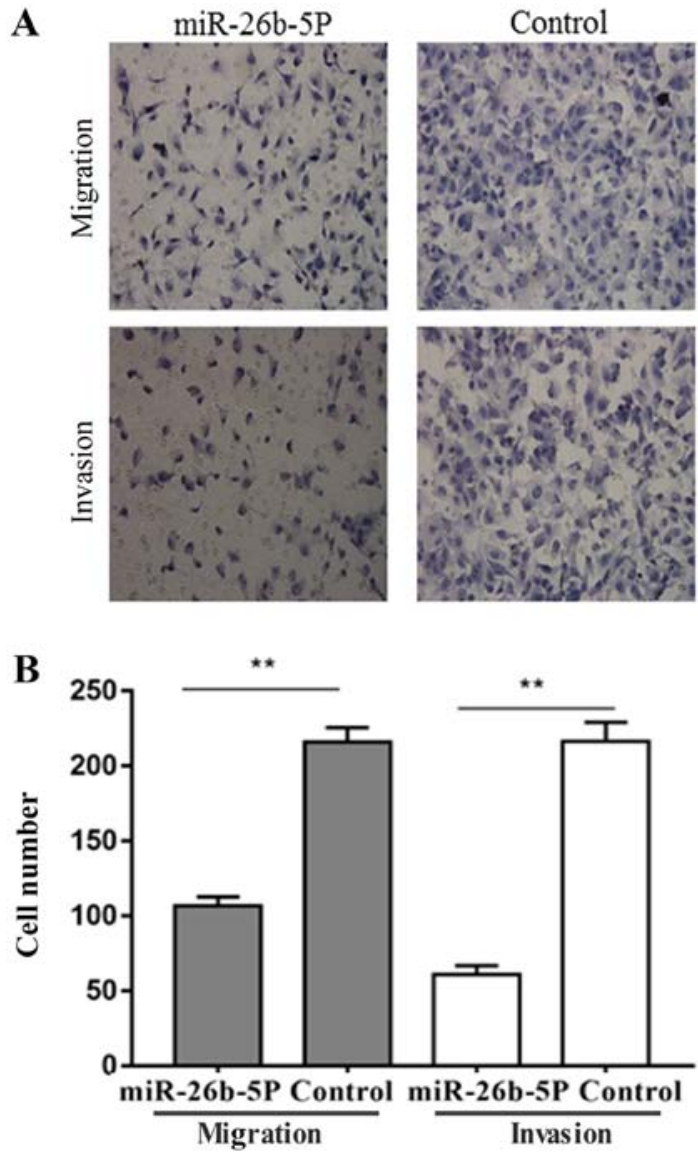

Figure 3. miR-26b-5p overexpression inhibits migration and invasion of B-CPAP cells. (A) Transwell and Matrigel assays were conducted to detect migration and invasion of B-CPAP cells with or without miR-26b-5p overexpression (magnification, $\mathrm{x} 200$ ). (B) Number of migratory and invasive $\mathrm{B}-\mathrm{CPAP}$ cells with or without miR-26b-5p overexpression. ${ }^{* *} \mathrm{P}<0.01$. miR-26b-5p, microRNA-26b-5p. 
A

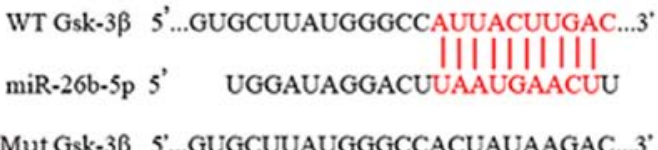

B

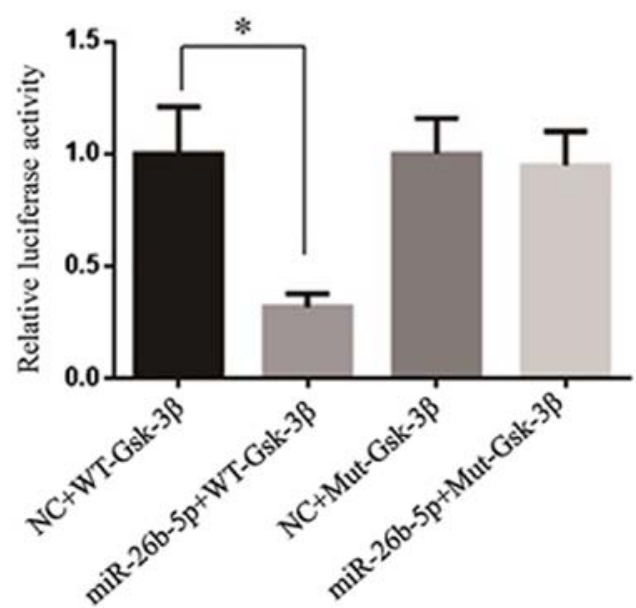

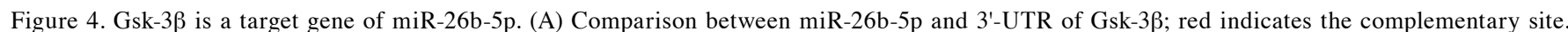

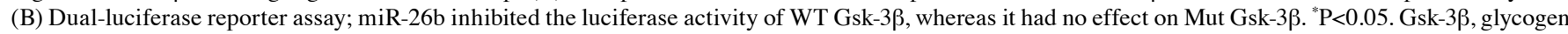
synthase kinase-3 $\beta$; miR-26b-5p, microRNA-26b-5p; Mut, mutant; NC, negative control; WT, wild-type.

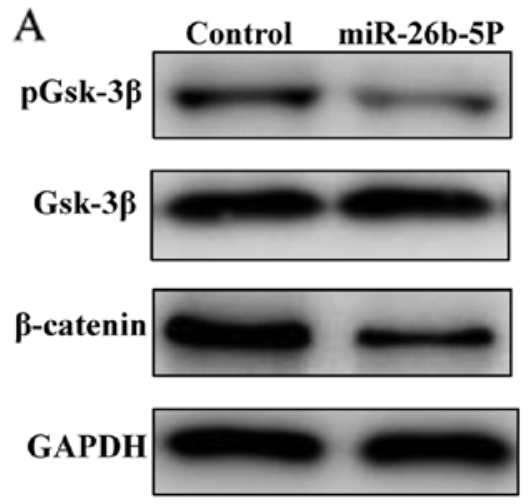

B

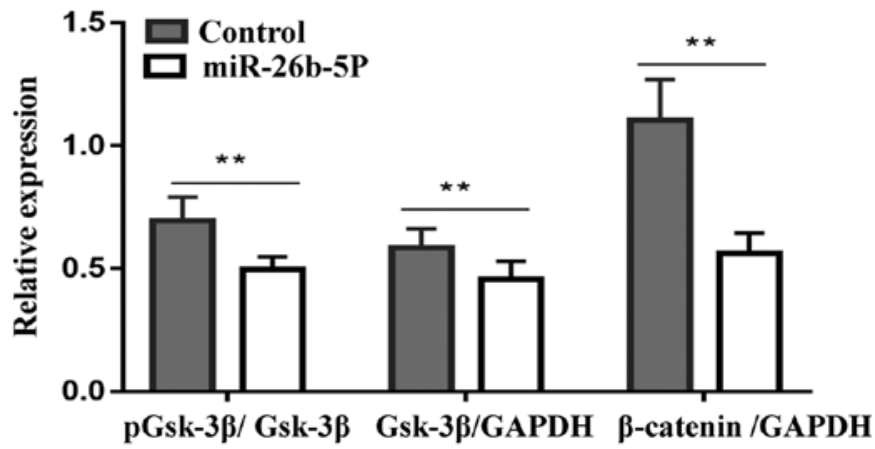

Figure 5. miR-26b-5p downregulates the protein expression levels of pGsk-3 $\beta$ and $\beta$-catenin in BCPAP cells. (A) Protein expression levels of Gsk-3 $\beta$, pGsk-3 $\beta$

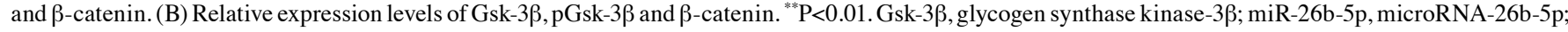
ns, not significant; p, phosphorylated.

\section{Discussion}

miRNAs may bind to specific target genes, and are involved in the regulation of tumor growth, differentiation, apoptosis and other processes $(22,23)$. Numerous miRNAs have been reported to be involved in the development of thyroid cancer, including miR-21, miR-338-3p, miR-221 and miR-146b-5p (24-27). Liu et al (28) revealed that miR-363-3p inhibits the proliferation, migration and invasion of TC by downregulating the expression of the target gene phosphatidylinositol-4,5-biphosphate 3-kinase catalytic subunit $\alpha$. Zhang et al (29) suggested that miR-146a may inhibit the expression of target gene protein kinase $\mathrm{C} \varepsilon$, and upregulated miR-146a expression promotes the apoptosis of TC cells. In addition, Yin et al (30) demonstrated that miR-195 may inhibit the proliferation and migration of B-CPAP and K1 TC cells by downregulating the expression of target genes cyclin D1 and fibroblast growth factor 2. Cheng et al (31) observed that overexpression of miR-150 inhibits the proliferation and invasion of tumor cells, and proposed that its target gene is Rho-associated coiled-coil containing protein kinase 1 . These results suggested that certain miRNAs are expressed at low levels in the majority of tumors and under physiological conditions, and may serve a role in inhibiting tumor proliferation and migration. Therefore, the overexpression of miRNAs may provide a novel strategy for the clinical treatment and diagnosis of thyroid cancer.

In the present study, the expression levels of miR-26b-5p were significantly downregulated in TC compared with in adjacent tissues. This result suggested that detecting the expression levels of miR-26b-5p may be used to distinguish cancer from normal thyroid tissue. In addition, the present results demonstrated that pre-operative detection of miR-26b-5p expression levels combined with biopsy results may be helpful in the diagnosis of TC. There was no significant association between miR-26b-5p expression and the sex, age, tumor size and TNM stage of patients; however, the expression levels of miR-26b-5p were significantly higher in TC tissues without lymph node metastasis compared with in tissues with lymph node metastasis.

To further examine the biological role of miR-26b-5p in TC, miR-26b-5p was overexpressed in the TC cell line B-CPAP. Cytological experiments demonstrated that miR-26b-5p overexpression may inhibit the proliferation, migration and invasion 
of B-CPAP cells, thus suggesting that miR-26b-5p may serve a negative regulatory role in the development of TC, which is consistent with previous studies. For example, Wu et al (16) reported that miR-26b-5p is downregulated in lung cancer, and overexpression of miR-26b-5p promotes tumor proliferation and inhibits apoptosis. Kato et al (32) demonstrated that miR-26a/b inhibits prostate cancer migration and invasion by regulating La-related protein 1 . Kozubek et al (33) revealed that miR-26b-5p expression is downregulated in melanoma, which may affect the progression of melanoma by regulating the mitogen-activated protein kinase pathway.

However, the molecular mechanism underlying the inhibitory effects of miR-26b-5p on TC remains unclear. TargetScan was used to predict the target gene of miR-26b-5p; Gsk-3 $\beta$ was identified as a potential target gene. The dual-luciferase enzyme assay confirmed that Gsk-3 $\beta$ may be a target of miR-26b-5p. Gsk-3 $\beta$ is an evolutionarily conserved serine/threonine kinase, which acts on numerous signaling proteins, structural proteins and transcription factors to regulate cell differentiation, proliferation, survival and apoptosis (34). Phosphorylation at different sites can regulate the activity of Gsk-3 $\beta$ : Phosphorylation at the 9 th serine can inhibit the activity of Gsk-3 $\beta$, and tyrosine phosphorylation at position 216 can enhance its activity (35). Gsk-3 $\beta$ substrates are widely involved in various physiological cell processes, and Gsk-3 $\beta$ serves a tumor-suppressing role in numerous types of cancer. Farago et al (36) demonstrated that following inhibition of Gsk-3 $\beta$ activity, the Wnt pathway is activated to promote breast cancer cell proliferation. Jiang et al (37) demonstrated that the expression levels of pGsk-3 $\beta^{\text {Ser9 }}$ are increased in lung cancer tissues, and that the expression levels of $\mathrm{pGsk}-3 \beta^{\mathrm{Ser} 9}$ are negatively correlated with lung cancer prognosis. Gsk-3 $\beta$ is a key kinase that determines the phosphorylation of $\beta$-catenin. An increase in Gsk-3 $\beta$ activity may promote the phosphorylation of $\beta$-catenin, which is degraded by the proteasome, resulting in antitumor effects. The anticancer effect of Gsk-3 $\beta$ is associated with obstruction of the Wnt signaling pathway, which is important for cell proliferation, differentiation and apoptosis (38). Further studies have demonstrated that the Wnt signaling pathway is involved in cell migration and invasion, and its regulation is associated with matrix metalloproteinase-7 (39), C-X-C motif chemokine receptor $4 \mathrm{~b}$ and $7 \mathrm{~b}(40)$. In the present study, the results demonstrated that the protein expression levels of pGsk-3 $\beta^{\text {Ser9 }}$ and $\beta$-catenin were significantly decreased in the miR-26b-5p overexpression group compared with in the empty vector group, so decreased phosphorylation could increase its activation. These findings suggested that miR-26b-5p may inhibit the proliferation, migration and invasion of B-CPAP cells via the Gsk-3 $\beta / \beta$-catenin pathway. Lv et al (41) demonstrated that miR-26a is consistently downregulated in TC specimens, whereas the upregulation of miR-26a in TC cells lines induces $\mathrm{G}_{2}$ phase cell cycle arrest by targeting and downregulating $\mathrm{CDC} 28$ protein kinase regulatory subunit 2 (CKS2), further research indicated that the negative regulatory effects are related to the CKS2 downstream genes cyclin A, $\mathrm{Bcl} 2$ like 1 and AKT. Lin et al (42) demonstrated that CKS2 regulates AKT and Gsk-3 $\beta$ phosphorylation. The present study suggested that miR-26b-5p may directly regulate Gsk-3 $\beta$; this may be associated with the mechanism underlying the effects of miR-26.
In conclusion, the present results suggested that miR-26b-5p was downregulated in TC tissues and was associated with lymph node metastasis. In addition, miR-26b-5p overexpression was able to inhibit the proliferation, migration and invasion of TC cells; these effects may be associated with the Gsk-3 $\beta / \beta$-catenin pathway. The present results further demonstrated that miR-26b-5p may provide a novel basis for the auxiliary diagnosis of TC, providing better individualized treatment. However, the mechanism by which miR-26b-5p is involved in tumorigenesis and development remains unclear and requires further study.

\section{Acknowledgements}

Not applicable.

\section{Funding}

This work was supported financially by the Shandong Key Research and Development Plan (grant no. 2017GSF18120) and the Jinan Science and Technology Development Plan (grant no. 201704105).

\section{Availability of data and materials}

The datasets used and/or analyzed during the current study are available from the corresponding author on reasonable request.

\section{Authors' contributions}

AZ, TW, and LL conceived and designed the project and prepared the manuscript. AZ, GC, XC, CZ and HX conducted the cell experiments. MQ and XC analyzed the data. All authors read and approved the manuscript.

\section{Ethics approval and consent to participate}

The study was approved by the Ethics Committee of The Shandong Provincial Hospital Affiliated to Shandong University, and all participants provided written informed consent.

\section{Patient consent for publication}

Not applicable.

\section{Competing interests}

The authors declare that they have no competing interests.

\section{References}

1. Randle RW, Bushman NM, Orne J, Balentine CJ, Wendt E, Saucke M, Pitt SC, Macdonald CL, Connor NP and Sippel RS: Papillary thyroid cancer: The good and bad of the 'Good Cancer'. Thyroid 27: 902-907, 2017.

2. Garau LM, Rubello D, Ferretti A, Boni G, Volterrani D and Manca G: Sentinel lymph node biopsy in small papillary thyroid cancer. A review on novel surgical techniques. Endocrine 62: 340-350, 2018.

3. Yan S, Zhao W, Wang B, Zhang L: Preoperative injection of carbon nanoparticles is beneficial to the patients with thyroid papillary carcinoma: From a prospective study of 102 cases. Medicine (Baltimore) 97: e11364, 2018. 
4. Paulsson JO, Zedenius J and Juhlin CC: Papillary thyroid carcinoma with pleomorphic tumor giant cells in a pregnant woman-a case report. BMC Endocr Disord 18: 46, 2018.

5. Yongfu Z, Ziyu L, Chen L and Jingchao X: Cervical mass as the initial manifestation of occult papillary thyroid carcinoma: Report of three cases. J Cancer Res Ther 14 (Suppl): S544-S548, 2018.

6. Hardin H, Helein H, Meyer K, Robertson S, Zhang R, Zhong W, Lloyd R: Thyroid cancer stem-like cell exosomes: Regulation of EMT via transfer of lncRNAs. Lab Invest 98: 1133-1142, 2018.

7. Ma B, Wei W, Xu W, Wang Y, Guan H, Fan J, Zhao Z, Wen D, Yang S, Wang Y, et al: Surgical confirmation of incomplete treatment for primary papillary thyroid carcinoma by percutaneous thermal ablation: A retrospective case review and literature review. Thyroid 28: 1134-1142, 2018.

8. Henn D, Abu-Halima M, Falkner F, Wermke D, Meme LG Kühner C, Keller A, Kneser U, Meese E, Schmidt V, et al: Micro-RNA regulated pro-angiogenic signaling in arteriovenous loops in patients with combined vascular and soft tissue reconstructions-reisiting the nutrient flap concept. Plast. Reconstr. Surg 142: 1, 2018.

9. Gomes A, da Silva IV, Rodrigues CMP, Castro RE and Soveral G: The emerging role of microRNAs in aquaporin regulation. Front Chem 6: 238, 2018.

10. Nigita G, Distefano R, Veneziano D, Romano G, Rahman M, Wang K, Pass H, Croce CM, Acunzo M and Nana-Sinkam P: Tissue and exosomal miRNA editing in non-small cell lung cancer. Sci Rep 8: 10222, 2018

11. Uen Y, Wang J, Wang C, Jhang Y, Chung J, Tseng T, Sheu M and Lee S: Mining of potential microRNAs with clinical correlation-regulation of syndecan-1 expression by miR-122-5p altered mobility of breast cancer cells and possible correlation with liver injury. Oncotarget 9: 28165-28175, 2018.

12. Liu DT, Yao HR, Li YY, Song YY and Su MY: MicroRNA-19b promotes the migration and invasion of ovarian cancer cells by inhibiting the PTEN/AKT signaling pathway. Oncol Lett 16 559-565, 2018.

13. Hersi HM, Raulf N, Gaken J, Folarin N and Tavassoli M: MicroRNA-9 inhibits growth and invasion of head and neck cancer cells and is a predictive biomarker of response to plerixafor, an inhibitor of its target CXCR4. Mol Oncol 12: 2023-2041, 2018.

14. Liu X, He M, Hou Y, Liang B, Zhao L, Ma S, Yu Y and Liu X: Expression profiles of microRNAs and their target genes in papillary thyroid carcinoma. Oncol Rep 29: 1415-1420, 2013.

15. Yang Z, Yuan Z, Fan Y, Deng X and Zheng Q: Integrated analyses of microRNA and mRNA expression profiles in aggressive papillary thyroid carcinoma. Mol Med Rep 8: 1353-1358, 2013.

16. Wu T, Chen W, Liu S, Lu H, Wang H, Kong D, Huang X, Kong Q, Ning Y and Lu Z: Huaier suppresses proliferation and induces apoptosis in human pulmonary cancer cells via upregulation of miR-26b-5p. FEBS Lett 588: 2107-2114, 2014.

17. Mei JY, Zhang MJ, Wang YY and Liu YH: The positive clinical therapeutically effects of Escin on advanced thyroid cancer. Cancer Med 6: 937-943, 2017.

18. Abbosh PH and Nephew KP: Multiple signaling pathways converge on beta-catenin in thyroid cancer. Thyroid 15: 551-561, 2005.

19. Livak KJ and Schmittgen TD: Analysis of relative gene expression data using real-time quantitative PCR and the 2 (-Delta Delta C(T)) method. Methods 25: 402-408, 2001.

20. Wakasa T, Li Y, Bai Y, Liu Z, Ozaki T, Mori I, Miyauchi A, Kakudo K and Nakamura M: Up-regulation of urinary-type plasminogen activator correlates with high-risk papillary thyroid carcinoma with BRAF(V600E) mutation and its possible molecular mechanism. Pathol Res Pract 210: 733-738, 2014.

21. Edge SB and Compton CC: The American Joint Committee on Cancer: The 7th edition of the AJCC cancer staging manualand the future of TNM. Ann Surg Oncol 17: 1471-1474, 2010.

22. Ambros V: MicroRNA pathways in flies and worms: Growth, death, fat, stress, and timing. Cell 113: 673-676, 2003

23. Farazi TA, Hoell JI, Morozov P and Tuschl T: MicroRNAs in human cancer. Adv Exp Med Biol 774: 1-20, 2013.

24. Menon MP and Khan A: Micro-RNAs in thyroid neoplasms: molecular, diagnostic and therapeutic implications. J Clin Pathol 62: 978-985, 2009.
25. Visone R, Russo L, Pallante P, De Martino I, Ferraro A, Leone V, Borbone E, Petrocca F, Alder H, Croce CM and Fusco A: MicroRNAs (miR)-221 and miR-222, both overexpressed in human thyroid papillary carcinomas, regulate p27Kip1 protein levels and cell cycle. Endocr Relat Cancer 14: 791-798, 2007.

26. Sui GQ, Fei D, Guo F, Zhen X, Luo Q, Yin S and Wang H: MicroRNA-338-3p inhibits thyroid cancer progression through targeting AKT3. Am J Cancer Res 7: 1177-1178, 2017.

27. Lima CR, Geraldo MV, Fuziwara CS, Kimura ET and Santos MF: miRNA-146b-5p upregulates migration and invasion of different Papillary Thyroid Carcinoma cells. BMC Cancer 16: $108,2016$.

28. Liu J, Li Q, Li R, Ren P and Dong S: MicroRNA-363-3p inhibits papillary thyroid carcinoma progression by targeting PIK3CA. Am J Cancer Res 7: 148-158, 2017.

29. Zhang X, Li D, Li M, Ye M, Ding L, Cai H, Fu D and Lv Z: MicroRNA-146a targets PRKCE to modulate papillary thyroid tumor development. Int J Cancer 134: 257-267, 2014.

30. Yin Y, Hong S, Yu S, Huang Y, Chen S, Liu Y, Zhang Q, Li Y and Xiao H: miR-195 inhibits tumor growth and metastasis in papillary thyroid carcinoma cell lines by targeting CCND1 and FGF2. Int J Endocrinol 2017: 6180425, 2017.

31. Cheng L, Zhou R, Chen M, Feng L and Li H: MicroRNA-150 targets Rho-associated protein kinase 1 to inhibit cell proliferation, migration and invasion in papillary thyroid carcinoma. Mol Med Rep 16: 2217-2224, 2017.

32. Kato M, Goto Y, Matsushita R, Kurozumi A, Fukumoto I, Nishikawa R, Sakamoto S, Enokida H, Nakagawa M, Ichikawa T and Seki N: MicroRNA-26a/b directly regulate La-related protein 1 and inhibit cancer cell invasion in prostate cancer. Int $\mathrm{J}$ Oncol 47: 710-718, 2015.

33. Kozubek J, Ma Z, Fleming E, Duggan T, Wu R, Shin DG and Dadras SS: In-depth characterization of microRNA transcriptome in melanoma. PLoS One 8: e72699, 2013.

34. Ikeda S, Kishida S, Yamamoto H, Murai H, Koyama $S$ and Kikuchi A: Axin, a negative regulator of the Wnt signaling pathway, forms a complex with GSK-3beta and beta-catenin and promotes GSK-3beta-dependent phosphorylation of beta-catenin. EMBO J 17: 1371-1384, 1998

35. Forde JE and Dale TC: Glycogen synthase kinase 3: A key regulator of cellular fate. Cell Mol Life Sci 64: 1930-1944, 2007.

36. Farago M, Dominguez I, Landesman-Bollag E, Xu X, Rosner A, Cardiff RD and Seldin DC: Kinase-inactive glycogen synthase kinase 3beta promotes Wnt signaling and mammary tumorigenesis. Cancer Res 65: 5792-5801, 2005.

37. Jiang Y, Miao J, Wang D, Zhou J, Liu B, Jiao F, Liang J, Wang Y, Fan $\mathrm{C}$ and Zhang Q: MAP30 promotes apoptosis of U251 and U87 cells by suppressing the LGR5 and Wnt//3-catenin signaling pathway, and enhancing Smac expression. Oncol Lett 15: 5833-5840, 2018.

38. Clevers $\mathrm{H}$ : Wnt/beta-catenin signaling in development and disease. Cell 127: 469-480, 2006.

39. Chen XJ, Meng J, Yue W, Yu J, Yang J, Yao Z and Zhang L: Fibulin-3 suppresses $\mathrm{Wnt} / \beta$-catenin signaling and lung cancer invasion. Carcinogenesis 35: 1707-1716, 2014

40. Aman A and Piotrowski T: Wnt/beta-catenin and Fgf signaling control collective cell migration by restricting chemokine receptor expression. Dev Cell 15: 749-761, 2008.

41. Lv M, Zhang X, Li M, Chen Q, Ye M, Liang W, Ding L, Cai H, Fu D and Lv Z: miR-26a and its target CKS2 modulate cell growth and tumorigenesis of papillary thyroid carcinoma. PLoS One 8: e67591, 2013.

42. Lin L, Fang Z, Lin H, Lin H, You H, Wang J, SU H, Wang F and Zhang ZY: Depletion of Cks1 and Cks2 expression compromises cell proliferation and enhance chemotherapy-induced apoptosis in HepG2 cells. Oncol Rep 35: 26-32, 2016.

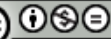

This work is licensed under a Creative Commons Attribution-NonCommercial-NoDerivatives 4.0 International (CC BY-NC-ND 4.0) License. 